\title{
Variation of human milk oligosaccharides in relation to milk groups and lactational periods
}

\author{
Stephan Thurl ${ }^{1}$, Manfred Munzert ${ }^{2}$, Jobst Henker ${ }^{3}$, Günther Boehm ${ }^{4,5}$, Beate Müller-Werner ${ }^{4}$, \\ Jürgen Jelinek ${ }^{4}$ and Bernd Stahl ${ }^{4}$ \\ ${ }^{1}$ Department of Food Technology, Fulda University of Applied Sciences, Marquardstrasse 35, 36039 Fulda, Germany \\ ${ }^{2}$ Bavarian State Research Centre for Agriculture, 85354 Freising, Germany \\ ${ }^{3}$ University Hospital Carl Gustav Carus, Technische Universität Dresden, 01304 Dresden, Germany \\ ${ }^{4}$ Danone Research, Centre for Specialised Nutrition, 61381 Friedrichsdorf, Germany \\ ${ }^{5}$ Sophia Children's Hospital, Erasmus University Rotterdam, 3000 DR Rotterdam, The Netherlands
}

(Received 13 January 2010 - Revised 30 March 2010 - Accepted 21 April 2010 - First published online 4 June 2010)

\begin{abstract}
Human milk oligosaccharides, representing the third largest fraction of human milk, have been assigned important protective functions for newborns acting as bifidogenic substrates or as inhibitory agents towards pathogens. Using high-pH anion-exchange chromatography and an enzyme test kit, twenty oligosaccharides and lactose were determined in milk samples of German women from days 3 to 90 postpartum. Twenty-two secretor mothers with Lewis blood group Le $(a-b+)$ synthesised all twenty oligosaccharides, and could be assigned to milk group 1. Five non-secretor mothers $(\operatorname{Le}(a+b-))$ produced all oligosaccharides with the exception of $\alpha 1,2$-fucosylated compounds (milk group 2), whereas three secretor mothers with blood type Le( $a-b-)$ lacked $\alpha 1,4$-fucosyloligosaccharides, corresponding to milk group 3 . Secretor women of milk groups 1 and 3 synthesised significantly higher amounts of total neutral oligosaccharides and of several total core structures (e.g. lacto- $N$-tetraose) than non-secretor women. Generally, these oligosaccharides significantly decrease during the first 3 months postpartum. By comparing fucosyloligosaccharides within and among the three milk groups, insight into their biosynthesis could be gained. Six acidic oligosaccharides without fucose residues were detected in milk samples of all mothers. Regression analysis confirmed that total acidic oligosaccharides declined threefold during the study period. Milk samples corresponding to the three milk groups exhibited significant qualitative and quantitative differences during the first 3 months of lactation. It can be assumed that particularly milk of non-secretor women (milk group 2) exerts a modified biological protection in the babies in comparison with milks of secretors (groups 1 and 3).
\end{abstract}

Oligosaccharides: Lactation: Milk groups: Fucosyltransferases: Sialyltransferases

The oligosaccharide fraction is the third largest constituent of human milk after lactose (Lac) and lipids. Colostrum is reported to contain 20-23 g/l oligosaccharides, and mature human milk is reported to contain $12-15 \mathrm{~g} / \mathrm{l}$ oligosaccharides $^{(1-3)}$. It can be assumed that the oligosaccharide fraction is extremely complex, consisting of at least 1000 different components, with most of them occurring in minor quantities $^{(4)}$. To date, more than eighty-five different oligosaccharide structures have been isolated and identified ${ }^{(5-8)}$. Most of these carbohydrates possess a Lac unit at the reducing end. Apart from Lac, several other core structures, for example, lacto- $N$-tetraose (LNT), lacto- $N$-neotetraose (LNnT), lacto$N$-hexaose (LNH), three further hexaoses, several octaoses and even decaoses, have been detected so far. These core structures are built from Lac by the addition of lacto$N$-biose units, that is Gal $\beta 1-3 \mathrm{GlcNAc}$ (type 1 structure), or lactosamine units, Gal $1-4 \mathrm{GlcNAc}$ (type 2 structure). Generally, these disaccharide units are either $\beta 1,3$-linked to one another or to Lac, resulting in elongated linear structures, or $\beta 1,6$-linked to inner galactose residues, thus building branched oligosaccharides. These core structures are substrates of various fucosyltransferases (FucT) and sialyltransferases in the mammary epithelial cells, and after being modified with fucosyl or sialyl moieties, they probably cannot be elongated or branched anymore ${ }^{(9)}$. Carbohydrates containing sialic acids or sulphate groups are classified as acidic oligosaccharides as opposed to the neutral oligosaccharide fraction comprising core structures as well as fucosylated carbohydrates.

Due to the specific action of several human $\alpha$-FucT, a variety of fucosylated carbohydrates are biosynthesised in various epithelial cells ${ }^{(10,11)}$. Similar oligosaccharide

Abbreviations: DF-LNH, difucosyl-lacto- $N$-hexaose; DSLNT, disialyl-lacto- $N$-tetraose; FL, fucosyl-lactose; FucT, fucosyltransferase; F-LNH, fucosyllacto- $N$-hexaose; HPAEC, high-pH anion-exchange chromatography; Lac, lactose; LDFT, lactodifucotetraose; LNDFH, lacto- $N$-difucohexaose; LNFP, lacto- $N$-fucopentaose; LNH, lacto- $N$-hexaose; LNT, lacto- $N$-tetraose; LNnT, lacto- $N$-neotetraose; LST, sialyl-lacto- $N$-tetraose; Neu5Ac, 5- $N$-acetylneuraminic acid; SL, sialyl-lactose.

* Corresponding author: S. Thurl, fax +49 6619640 505, email stephan.thurl@1t.hs-fulda.de 
structures that are closely related to the Lewis blood group system can thus be detected on erythrocytes and in saliva as well as in human milk ${ }^{(12)}$. Four different milk groups had been described in accordance with specific Lewis blood group-dependent oligosaccharide patterns ${ }^{(13,14)}$. In addition to neutral carbohydrates, a variety of acidic oligosaccharides have been found to occur in human milk in relatively low amounts of $1.5-3 \cdot 3 \mathrm{~g} / \mathrm{l}^{(15)}$. They contain mostly $5-\mathrm{N}$-acetylneuraminic acid (Neu5Ac), a predominant member of the sialic acid family. $\alpha 2,3-$ Sialylation occurs on terminal galactoses of type 1 structures and of Lac. $\alpha 2,6-$ Linked Neu5Ac has been detected on terminal galactoses of type 2 structures and of Lac, as well as on subterminal $\mathrm{N}$-acetylglucosamine of type 1 structures ${ }^{(8,13,16)}$.

Several biological functions of human oligosaccharides, such as prebiotic, anti-adhesive, glycome-modifying and anti-inflammatory effects, have been postulated so far ${ }^{(17,18)}$. Some evidence exists that the oligosaccharides may protect breast-fed infants from pathogenic bacteria, viruses, toxins, protozoa and fungi by acting as soluble receptor analogues that prevent the interaction of pathogens with epithelial cells at the initial stage of infections ${ }^{(19,20)}$. Furthermore, these oligosaccharides may act as prebiotics. $\mathrm{N}$-acetylglucosaminecontaining oligosaccharides have been reported to promote the growth of Bifidobacterium bifidum, thereby suppressing the growth of undesirable bacteria ${ }^{(21-23)}$.

A prerequisite for a profound understanding of the biological role of human milk oligosaccharides is detailed knowledge of their composition and quantities. The first quantitative determinations of oligosaccharides were carried out by Montreuil \& Mullet $^{(1)}$. This examination and the studies done by Viverge et al. ${ }^{(2,24)}$ were performed with a few women using paper chromatography or gel permeation chromatography in combination with colorimetric methods. In the last 15 years, some more detailed studies were performed applying various chromatographic methods for the determination of neutral oligosaccharides during the course of lactation ${ }^{(3,15,25-28)}$. To date, only few examinations were carried out in order to quantify acidic oligosaccharides ${ }^{(15,29-31)}$. In the present study, an efficient high-pH anion-exchange chromatographic (HPAEC) method ${ }^{(25,32)}$ was used to analyse about 175 milk samples from German women during the first 3 months of lactation. This investigation was aimed to broaden the biological knowledge of the composition of milk oligosaccharides, especially with regard to the four milk groups ${ }^{(14)}$. Furthermore, more detailed facts about these important human milk components will be helpful for the development of better adapted milk formulas.

\section{Subjects and methods}

\section{Serological tests}

The Lewis blood groups of the women were determined within $3 \mathrm{~d}$ postpartum on the day of blood sampling by a haemagglutination tube test. Haemagglutination was examined using corresponding erythrocyte suspensions (3-5\% erythrocytes suspended in $0.9 \% \mathrm{NaCl})$ and monoclonal anti-Le ${ }^{\mathrm{a}}$ and anti-Le ${ }^{b}$ antibodies (Immucor, Rödermark, Germany and BAG, Lich, Germany). Incubation was done at room temperature for $15 \mathrm{~min}$. Due to discrepancies between serological tests and chromatographic profiles, some haemagglutination tests were repeated $18-25$ months postpartum ${ }^{(33)}$. The women were not pregnant at that time.

\section{Collection of samples}

The present study was conducted according to the guidelines laid down in the Declaration of Helsinki, and all procedures involving human subjects/patients were approved by the ethical committee of the University Hospital of Dresden, Germany. All mothers had given written consent for their participation in the present study. The thirty Caucasian women were living in the region of Dresden; they were between 20 and 35 years old and had given birth to healthy infants who were exclusively breast-fed during the study period. One hundred and seventy-five breast milk samples were taken predominantly on and around seven predetermined days: day 3, 2-5 d postpartum; day 8 , d6-d9; day $15, \mathrm{~d} 13-\mathrm{d} 18$; day 22 , d20-d26; day 30, d28-d33; day 60, d57-d65; and day 90, $\mathrm{d} 88$ - d96. In cases where the mothers provided more than one milk sample corresponding to the above-mentioned time intervals, all the samples were analysed for oligosaccharide concentrations, which were expressed as the arithmetic mean values. In a preexamination with six volunteers (Lewis blood type $\operatorname{Le}(a-b+))$ from the region of Frankfurt/Main, Germany, we could not find any significant oligosaccharide variation during two $24 \mathrm{~h}$ periods at days 7 and 60 postpartum (data not shown). In order to exclude even small diurnal effects $^{(34)}$, the milk samples were generally collected during the morning hours between 06.00 and 10.00 hours by applying the mid-feed sampling technique, which was shown previously to be an adequate method for carbohydrate analysis ${ }^{(35,36)}$. About $5-10 \mathrm{ml}$ aliquots were expressed manually in the middle of feeding into plastic containers. Milk samples were immediately frozen, and stored at $-20^{\circ} \mathrm{C}$ until analysis.

\section{Chromatographic analysis of oligosaccharides}

Sample preparation, including gel permeation chromatographic purification, as well as HPAEC analyses was performed as described previously ${ }^{(32)}$. Briefly, human milk samples were heated for $30 \mathrm{~min}$ at $70^{\circ} \mathrm{C}$. One millilitre of human milk was added to $0 \cdot 1 \mathrm{ml}$ of an aqueous solution containing the internal standards stachyose and galacturonic acid. The samples were subsequently centrifuged and ultrafiltrated (Centrifree, 30 kDa cut-off; Millipore, Schwalbach, Germany). The protein- and lipid-reduced samples were fractionated by gel permeation chromatography using Toyopearl HW 40 (S) columns $(1.6 \times 80 \mathrm{~cm}$; TosoHaas, Stuttgart, Germany). The carbohydrate fractions were eluted with water (flow rate of $1 \mathrm{ml} / \mathrm{min}$ ), and monitored by refractive index detection. The major portion of Lac could be removed from the neutral oligosaccharide fraction ${ }^{(32)}$. Acidic, negatively charged oligosaccharides, eluting near the void volume of the gel permeation column, were clearly separated from the major neutral oligosaccharides determined in the present study. Both neutral and acidic fractions were analysed separately by HPAEC coupled with a pulsed electrochemical detector. Oligosaccharides were identified and quantified using standard substances as well as the internal standards stachyose and galacturonic acid. The calculations done for oligosaccharide concentrations were based on individual molar response factors that had been 
determined previously ${ }^{(32)}$. The eluents used for the analysis of neutral oligosaccharides were $0-20 \mathrm{~min}, 30 \mathrm{~mm}-\mathrm{NaOH}$; 20-34 min, 30-100 mM-NaOH; 34-48 min, $100 \mathrm{~mm}-\mathrm{NaOH} /$ 0-28 mu-NaOAc; $48-55 \mathrm{~min}, 100 \mathrm{~mm}-\mathrm{NaOH} / 28-200 \mathrm{~mm}-$ $\mathrm{NaOAc}$; and 55-60 min, $100 \mathrm{~mm}-\mathrm{NaOH} / 200 \mathrm{~mm}-\mathrm{NaOAc}$. In addition, most neutral oligosaccharide fractions were analysed a second time with a different gradient (0-12 min, $60 \mathrm{~mm}-\mathrm{NaOH}$; $12-16 \mathrm{~min}, 60-100 \mathrm{~mm}-\mathrm{NaOH} ; 16-30 \mathrm{~min}$, $100 \mathrm{~mm}-\mathrm{NaOH} / 0-28 \mathrm{~mm}-\mathrm{NaOAc}$; $30-35 \mathrm{~min}, 100 \mathrm{~mm}-\mathrm{NaOH} /$ 28-200 mM-NaOAc; and 35-40 min, $100 \mathrm{~mm}-\mathrm{NaOH} / 200 \mathrm{~mm}-$ $\mathrm{NaOAc}$ ) allowing separation and quantification of the coeluting neutral oligosaccharides 3-fucosyl-lactose (FL) and lacto- $N$-difucohexaose (LNDFH) I. In contrast to the abovementioned publication ${ }^{(32)}$, this additional step was necessary due to altered performances of the CarboPac PA-100 columns (Dionex, Idstein, Germany) used during the study.

The elution conditions for acidic oligosaccharides were $0-8 \mathrm{~min}, \quad 100 \mathrm{~mm}-\mathrm{NaOH} / 20 \mathrm{~mm}-\mathrm{NaOAc} ; 8-30 \mathrm{~min}$, $100 \mathrm{~mm}-\mathrm{NaOH} / 20-80 \mathrm{~mm}-\mathrm{NaOAc} ; \quad 30-55 \mathrm{~min}, 100 \mathrm{~mm}-$ $\mathrm{NaOH} / 80-200 \mathrm{~mm}-\mathrm{NaOAc}$; and 55-60 min, $100 \mathrm{~mm}-\mathrm{NaOH} /$ $200 \mathrm{~mm}-\mathrm{NaOAc}$. In order to monitor possible artificial hydrolytic degradation of especially susceptible sialyloligosaccharides, free Neu5Ac was quantified along with acidic oligosaccharides. Neu5Ac concentrations were relatively constant (average concentration of $0.019 \mathrm{~g} / 1$ in milk group 1; data not shown). The amounts of free Neu5Ac were of the same magnitude as reported previously ${ }^{(37)}$, and correspond to approximately 2 and $4 \%$ of oligosaccharide-bound Neu5Ac at the beginning of lactation and after 3 months, respectively. Therefore, significant degradation of acidic oligosaccharides due to the action of sialidases or to heat treatment can be excluded ${ }^{(38)}$.

\section{Determination of lactose}

Two hundred and fifty microlitres of human milk were mixed with deionised water and with $1 \mathrm{ml}$ Carrez-I-solution $(85 \mathrm{~mm}-$ $\left.\mathrm{K}_{4}\left[\mathrm{Fe}(\mathrm{CN})_{6}\right]\right)$ and $1 \mathrm{ml}$ Carrez-II-solution $\left(250 \mathrm{~mm}-\mathrm{ZnSO}_{4}\right)$ in a $25 \mathrm{ml}$ volumetric flask. After filtration, Lac concentrations of the diluted (factor 100) and protein- and lipid-reduced milk samples were determined using a Lac/D-galactose test combination obtained from R-Biopharm, Darmstadt, Germany ${ }^{(39)}$. $\beta$-Galactosidase released galactose which was subsequently oxidised by galactose dehydrogenase. Lac concentrations could be calculated with the UV absorbances of the reduced cofactor nicotinamide adenine dinucleotide at $340 \mathrm{~nm}$.

\section{Statistical analyses}

Data that were analysed by statistical methods consisted either of concentrations of individual oligosaccharides or of sums of various carbohydrates. Apart from total neutral and total acidic oligosaccharides, the following total core structures and fucosylated carbohydrates were summed up, respectively:

$$
\begin{aligned}
& \text { total core } \mathrm{Lac}=\mathrm{Lac}+3-\mathrm{FL}+2^{\prime}-\mathrm{FL}+\mathrm{LDFT}+3^{\prime}-\mathrm{SL} \\
& \quad+6^{\prime}-\mathrm{SL} ; \\
& \text { total core } \mathrm{LNT}=\mathrm{LNT}+\mathrm{LNFP} \mathrm{I}+\mathrm{LNFP} \mathrm{II}+\mathrm{LNDFH} \mathrm{I} \\
& \quad+\mathrm{LNDFH} \mathrm{II}+\mathrm{LSTa}+\mathrm{LSTb}+\mathrm{DSLNT} ; \\
& \text { total core } \mathrm{LNnT}=\mathrm{LNnT}+\mathrm{LNFP} \mathrm{III}+\mathrm{LSTc} \\
& \text { total core } \mathrm{LNH}=\mathrm{LNH}+2^{\prime}-\mathrm{F}-\mathrm{LNH}+3^{\prime}-\mathrm{F}-\mathrm{LNH} \\
& \quad+2^{\prime}, 3^{\prime}-\mathrm{DF}-\mathrm{LNH} ;
\end{aligned}
$$

$$
\begin{aligned}
& \text { Fuc } \alpha 1-2 \mathrm{Gal}=2^{\prime}-\mathrm{FL}+\mathrm{LDFT}+\mathrm{LNFP} \mathrm{I}+\mathrm{LNDFH} \mathrm{I} \\
& \quad+2^{\prime} \text {-F-LNH }+2^{\prime}, 3^{\prime} \text {-DF-LNH; }
\end{aligned}
$$$$
\text { Fuc } \alpha 1-4 \text { GlcNAc }=\text { LNFP II + LNDFH I + LNDFH II; }
$$$$
\text { Fuc } \alpha 1-3 \text { Glc }=3-\text { FL }+ \text { LDFT }+ \text { LNDFH II; }
$$$$
\text { Fuc } \alpha 1-3 \text { GlcNAc }=\text { LNFP III }+3^{\prime}-\text { F-LNH }+2^{\prime}, 3^{\prime}-\text { DF-LNH; }
$$

where LDFT, lactodifucotetraose; SL, sialyl-lactose; LNFP, lacto- $N$-fucopentaose; LST, sialyl-lacto- $N$-tetraose; DSLNT, disialyl-lacto- $N$-tetraose; $\quad$ F-LNH, fucosyl-lacto- $N$-hexaose; DF-LNH, difucosyl-lacto- $N$-hexaose; Fuc $\alpha 1-2$ Gal, $\alpha 1,2$-fucose linked to terminal galactose; Fuc $\alpha 1-4$ GlcNAc, $\alpha 1,4$-fucose linked to subterminal $N$-acetylglucosamine; Fuc $\alpha 1-3 \mathrm{Glc}, \alpha 1$, 3 -fucose linked to reducing glucose; Fuc $\alpha 1-3$ GlcNAc, $\alpha 1$, 3-fucose linked to subterminal GlcNAc.

The data set is two-factorially organised in the three milk groups and seven lactation times, respectively. Besides, the data set is very unbalanced due to different sample numbers. In milk group 1, 109 samples were assigned into groups according to lactation times, and each group contained between ten and twenty-one samples, whereas in group 2 (twenty-eight samples), the lactation times were represented by three to five samples, and in group 3 (seventeen samples), they were represented by two to three samples. Therefore, several methods were applied for analysing the means of oligosaccharide concentrations. In the case of milk group 1, a one-factorial ANOVA followed by the Student-NewmanKeuls test was used to compare the mean values of lactation times. By comparing the averages of the three milk groups, a two-factorial ANOVA with type III sums of squares was applied, and then least-squares means were calculated. So, the group averages are unbiased and completely comparable together. Differences between averages were tested using the Tukey-Kramer method on a significance level of $P=0 \cdot 05$. In both variance models, the differences between the sample concentrations of the participating women per group and time yielded the experimental error. Generally, oligosaccharide concentrations of milks from women of the same milk group at a given lactation period were highly variable. Due to these large interindividual variations, in some cases, no significant differences between means $(P>0.05)$ were found despite seemingly clear differences.

Trends of oligosaccharide concentrations during lactation were modelled by regression analysis. Simple linear regression as well as polynomial regression of second and third degree was fitted and tested on significant coefficients of regression. The model was accepted if the coefficients of regression were significant $(P<0 \cdot 05)$. All analyses of regression were carried out with the individual values, although only the mean values are drawn in Figs. 2 and 3 for clarification purposes. All computations were done using the SAS System (SAS Institute, Cary, NC, USA) ${ }^{(40)}$.

\section{Results}

\section{Lewis blood groups and oligosaccharide profiles}

According to haemagglutination tests, twenty-two donors (73\%) revealed Lewis blood type $\operatorname{Le}(\mathrm{a}-\mathrm{b}+)$, and five donors $(17 \%)$ were determined as having Lewis blood type $\operatorname{Le}(a+b-)$, whereas three women $(10 \%)$ were $\operatorname{Le}(\mathrm{a}-\mathrm{b}-)$ donors. These proportions were in a range that was similar to the frequencies of Lewis blood groups among the European populations ${ }^{(10,24,41)}$. 
Table 1. Structures of the neutral milk oligosaccharides determined in the present study and their relation to milk groups $1-3$

\begin{tabular}{|c|c|c|c|c|c|c|}
\hline \multirow[b]{2}{*}{ Peak } & \multirow[b]{2}{*}{ Name (abbreviated) } & \multirow[b]{2}{*}{ Structure } & \multirow[b]{2}{*}{ Antigen } & \multicolumn{3}{|c|}{ Milk group } \\
\hline & & & & 1 & 2 & 3 \\
\hline 1 & $2^{\prime}-\mathrm{FL}$ & Fuc $\alpha 1-2 \mathrm{Gal} \beta 1-4 \mathrm{Glc}$ & $\mathrm{H}-2_{\mathrm{ga}}$ & + & - & + \\
\hline 2 & 3-FL & $\begin{array}{l}\text { Gal } \beta 1-4 \text { Glc } \\
\text { Fuc } \alpha 1-3 /\end{array}$ & $\operatorname{Le}^{x_{g a}}$ & + & + & + \\
\hline 3 & LDFT & $\begin{array}{r}\text { Fuc } \alpha 1-2 \text { Gal } \beta 1-4 \text { Glc } \\
\text { Fuc } \alpha 1-3 /\end{array}$ & $\operatorname{Le}_{\text {ga }}^{y}$ & + & - & + \\
\hline 4 & LNT & Gal $\beta 1-3 G|c N A c \beta 1-3 G a l \beta 1-4 G| c$ & & + & + & + \\
\hline 5 & LNnT & Gal $\beta 1-4 \mathrm{GlcNAc} \beta 1-3 \mathrm{Gal} \beta 1-4 \mathrm{Glc}$ & & + & + & + \\
\hline 6 & LNFP I & Fuc $\alpha 1-2 \mathrm{Gal} \beta 1-3 \mathrm{GlcNAc} \beta 1-3 \mathrm{Gal} \beta 1-4 \mathrm{Glc}$ & $\mathrm{H}-1$ & + & - & + \\
\hline 7 & LNFP II & $\begin{array}{l}\text { Gal } \beta 1-3 \mathrm{GICNAc} \beta 1-3 \mathrm{Gal} \beta 1-4 \mathrm{GIC} \\
\text { Fuc } \alpha 1-4 /\end{array}$ & $\mathrm{Le}^{\mathrm{a}}$ & + & + & - \\
\hline 8 & LNFP III & $\begin{array}{l}\text { Gal } \beta 1-4 \mathrm{GlcNAc} \beta 1-3 \mathrm{Gal} \beta 1-4 \mathrm{Glc} \\
\text { Fuc } \alpha 1-3 /\end{array}$ & $\operatorname{Le}^{x}$ & + & + & + \\
\hline 9 & LNDFH I & $\begin{array}{l}\text { Fuc } \alpha 1-2 \mathrm{Gal} \beta 1-3 \mathrm{GlcNAc} \beta 1-3 \mathrm{Gal} \beta 1-4 \mathrm{Glc} \\
\text { Fuc } \alpha 1-4 /\end{array}$ & $\mathrm{Le}^{\mathrm{b}}$ & + & - & - \\
\hline 10 & LNDFH II & 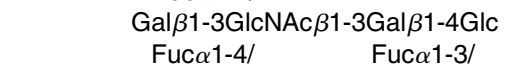 & $\mathrm{Le}^{\mathrm{a}}$ & + & + & - \\
\hline 11 & LNH & $\begin{array}{l}\text { Gal } \beta 1-4 \mathrm{GlcNAc} \beta 1-6 \mid \\
\mathrm{Gal} \beta 1-3 \mathrm{GlcNAc} \beta 1-3 \mathrm{Gal} \beta 1-4 \mathrm{Glc}\end{array}$ & & + & + & + \\
\hline 12 & $2^{\prime}-\mathrm{F}-\mathrm{LNH}$ & $\begin{array}{c}\text { Gal } \beta 1-4 \mathrm{GlcNAc} \beta 1-6 \mid \\
\text { Fuc } \alpha 1-2 \mathrm{Gal} \beta 1-3 \mathrm{GlcNAc} \beta 1-3 \mathrm{Gal} \beta 1-4 \mathrm{Glc}\end{array}$ & $\mathrm{H}-1$ & + & - & + \\
\hline 13 & $3^{\prime}-\mathrm{F}-\mathrm{LNH}$ & $\begin{array}{l}\text { Fuc } \alpha 1-3 \mid \\
\text { Gal } \beta 1-4 \mathrm{GlcNAc} \beta 1-6 \mid \\
\text { Gal } \beta 1-3 \mathrm{GlcNAc} \beta 1-3 \mathrm{Gal} \beta 1-4 \mathrm{Glc}\end{array}$ & $\operatorname{Le}^{x}$ & + & + & + \\
\hline 14 & $2^{\prime}, 3^{\prime}-\mathrm{DF}-\mathrm{LNH}$ & $\begin{array}{c}\text { Fuc } \alpha 1-3 \mid \\
\text { Gal } \beta 1-4 G|c N A c \beta 1-6| \\
\text { Fuc } \alpha 1-2 \text { Gal } \beta 1-3 G|c N A c \beta 1-3 G a l \beta 1-4 G| c\end{array}$ & $H-1 / L e^{x}$ & + & - & + \\
\hline
\end{tabular}

2'-FL, 2'-fucosyl-lactose; 3-FL, 3-fucosyl-lactose; LDFT, lactodifucotetraose; LNT, lacto- $N$-tetraose; LNnT, lacto- $N$-neotetraose; LNFP I-III, lacto- $N$-fucopentaoses I-III; LNDFH I-II, lacto- $N$-difucohexaoses I-II; LNH, lacto- $N$-hexaose; 2'-F-LNH, 2'-fucosyl-lacto- $N$-hexaose; $3^{\prime}$-F-LNH, $3^{\prime}$-fucosyl-lacto- $N$-hexaose; $2^{\prime}, 3^{\prime}$-DF-LNH, $2^{\prime}, 3^{\prime}$-difucosyl-lacto- $N$-hexaose; $\mathrm{H}-2_{\text {ga }}$, glucose analogue of $\mathrm{H}-2$ antigen ${ }^{(28)}$; Le ${ }^{\mathrm{x}}$ ga, glucose analogue of $\mathrm{Le}^{\mathrm{x}}$ antigen; $\mathrm{Le}_{\mathrm{y}}^{\mathrm{y}}$ ga, glucose analogue of $\mathrm{Le}^{\mathrm{y}}$ antigen; ' + ', the presence of the corresponding oligosaccharide; '-', the absence of the corresponding oligosaccharide.

Applying an HPAEC method, fourteen neutral oligosaccharides listed in Table 1 could be determined (Fig. 1(a)). In accordance with their Lewis blood group Le $(a-b+)$, milk samples of twenty-two donors exhibited all these fourteen structures including $\alpha 1,2-, \alpha 1,4-$ and $\alpha 1,3$-fucosyloligosaccharides. Milk samples revealing this oligosaccharide pattern were assigned to milk group $1^{(13,14)}$. Milk samples of the five non-secretor women (Lewis blood type Le $(\mathrm{a}+\mathrm{b}-)$ ) lacked 2'-FL, LDFT, LNFP I, LNDFH I, 2'-F-LNH and 2',3'-DF-LNH, and were assigned to milk group 2 because no $\alpha 1,2$-fucosyloligosaccharides were detected (Fig. 1(b) and Table 1). In the milk samples of three mothers with Lewis blood type $\operatorname{Le}(\mathrm{a}-\mathrm{b}-), \alpha 1,2$ - and $\alpha 1,3$-fucosyloligosaccharides were found, whereas LNFP II, LNDFH I and LNDFH II with $\alpha 1$,4-fucose residues were missing (Fig. 1(c). One of these women (B. A.) also lacked LDFT, a fucosylated component typical for this milk group, and $3-\mathrm{F}^{\prime}-\mathrm{LNH}$, which was normally detected in all milk samples. In spite of these minor deviations, all three mothers were assigned to milk group 3 (Table 1). None of the thirty women in the present study exhibited an oligosaccharide profile without $\alpha 1,2$-linked and $\alpha 1,4$-linked fucosyloligosaccharides, corresponding to milk group $4^{(14)}$. This is in agreement with the low prevalence $(1 \%)$ of the genotype se/se and le/le among Caucasian women ${ }^{(10)}$.

\section{Carbohydrate fractions}

In Table 2, average concentrations of the major carbohydrate fractions are listed. Lac concentrations determined enzymatically were similar in milk samples of all three milk groups. During the study period, concentrations remained constant in mature milk (milk group 1: $57-60 \mathrm{~g} / 1$; data not shown), whereas colostral milk at day 3 postpartum contained significantly lower amounts of Lac (average concentration of $50 \cdot 3 \mathrm{~g} / \mathrm{l}$ in milk group 1 ).

The sum of the fourteen major neutral oligosaccharides determined by chromatographic analysis approximately represents the neutral oligosaccharide fraction of human milk (Table 1). This carbohydrate fraction is relatively abundant in secretor milks, especially in milk group 3, whereas non-secretors (milk group 2) only produce approximately half the amount (Table 2). In Fig. 2, the variation of neutral oligosaccharides during the course of lactation is shown. The concentration of neutral oligosaccharides in both secretor milks (groups 1 and 3) steadily decreased during the first $90 \mathrm{~d}$ postpartum, as indicated by two significant declining straight lines, calculated by regression analysis. In contrast, neutral oligosaccharides in non-secretor milks seemed to remain relatively constant during the study period.

In addition to neutral oligosaccharides, six major nonfucosylated acidic oligosaccharides, $3^{\prime}-\mathrm{SL}, 6^{\prime}-\mathrm{SL}, \mathrm{LSTa}$, LSTb, LSTc and DSLNT, as listed in Table 3, could be determined chromatographically. The sum of these carbohydrates approximately represents the acidic oligosaccharide fraction of human milk. Because of the importance of the Lewis blood group system, these oligosaccharides were also examined separately according to the three milk groups. 
(a)
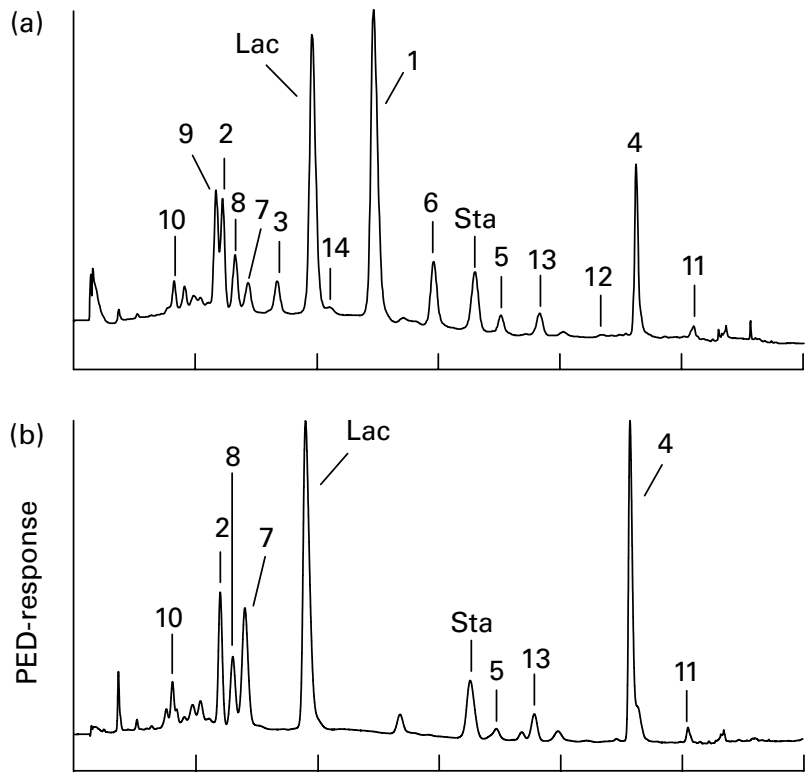

(c)

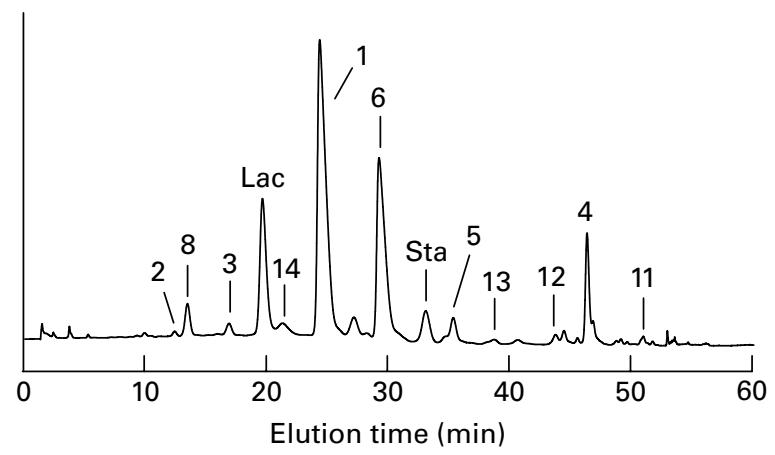

Fig. 1. High-pH anion-exchange chromatography profiles of neutral oligosaccharide fractions from (a) $a \mathrm{Le}(a-b+)$ donor, corresponding to milk group 1, (b) a Le $(a+b-)$ donor, corresponding to milk group 2, and (c) a Le $(a-b-)$ donor, corresponding to milk group 3 . The peak numbers correspond to the following milk oligosaccharides: 1, 2'-FL; 2, 3-FL; 3, LDFT; 4, LNT; 5, LNnT; 6, LNFP I; 7, LNFP II; 8, LNFP III; 9, LNDFH I; 10, LNDFH II; 11, LNH; 12, 2'-F-LNH; 13, 3'-F-LNH; and 14, 2', $3^{\prime}$-DF-LNH; Lac, lactose; Sta, stachyose; PED, pulsed electrochemical detector.

Milk samples of all three milk types exhibited the above-mentioned six acidic oligosaccharides. The quantities of the acidic oligosaccharide fractions did not differ significantly among the three milk groups (Table 2). In addition, all milk groups exhibited an almost parallel decrease to one-third of the initial acidic sugar concentrations during the study period (Fig. 2).

\section{Core structures}

In Table 4, a comparison of the molar concentrations of Lac, LNT, LNnT and LNH with the amounts of the corresponding total core oligosaccharides, comprising not only the former basic structures but also their fucosylated and sialylated derivatives, is given. The knowledge of the total core structures, representing the real biosynthetic capacity of the milk-producing epithelial cells, is a prerequisite for a profound discussion of the action of various FucT and sialyltransferases. Total core Lac, which can be interpreted as a glucose analogue of type 2 chains ${ }^{(28)}$, was by far the most abundant core
Table 2. Average concentrations ( $\mathrm{g} / \mathrm{l}$ ) of oligosaccharide fractions

\begin{tabular}{lcccc}
\hline Milk group & $n$ & $\begin{array}{c}\text { Neutral } \\
\text { oligosaccharides }\end{array}$ & $\begin{array}{c}\text { Acidic } \\
\text { oligosaccharides }\end{array}$ & Lactose* $^{*}$ \\
\hline 1 & 109 & $9 \cdot 51^{\mathrm{b}}$ & $2 \cdot 23^{\mathrm{a}}$ & $56 \cdot 8^{\mathrm{a}}$ \\
2 & 28 & $5 \cdot 58^{\mathrm{c}}$ & $2 \cdot 17^{\mathrm{a}}$ & $58 \cdot 2^{\mathrm{a}}$ \\
3 & 17 & $10 \cdot 53^{\mathrm{a}}$ & $2 \cdot 48^{\mathrm{a}}$ & $55 \cdot 4^{\mathrm{a}}$ \\
\hline a,b,c Least-squares means (as a consequence of unbalanced data) & within a \\
column with unlike superscript letters were significantly different & $(P<0.05 ;$ \\
the Tukey-Kramer test). \\
* In some cases, the numbers of samples were slightly reduced.
\end{tabular}

structure exceeding total core LNT, a type 1 structure, on average by a factor of 34 (group 1 in Table 4). Total core LNnT, a typical type 2 structure, and total core LNH were detected in even lower quantities. Lac was found to be the prevalent form (about $95 \%$ ) of the core Lac structure. In contrast, unmodified LNT, LNnT and LNH varied from 17 to $31 \%$ in relation to the corresponding total core structures. Obviously, fucosylated and sialylated oligosaccharides are the predominant forms of these three basic components.

LNT was expressed in higher amounts in non-secretor milks (group 2) than in secretor milks (groups 1 and 3), but when comparing total core LNT, it turned out that non-secretor mothers synthesised significantly lower amounts of this core structure (Table 4). Non-secretor women also produced significantly lower concentrations of the total core structures LNnT and LNH, roughly 75 and $55 \%$ of the amounts detected in milk group 1 , respectively. In contrast, total core Lac did not differ significantly among the three milk groups. Concentrations of total core LNT, total core LNnT and total core LNH in milk group 1 significantly decreased during the study period. However, colostrum exhibited significantly lower amounts of total core LNT and total core LNH than transitional milk at day 8 postpartum. For the purpose of clarity, time effects are listed in Table 4 only within milk

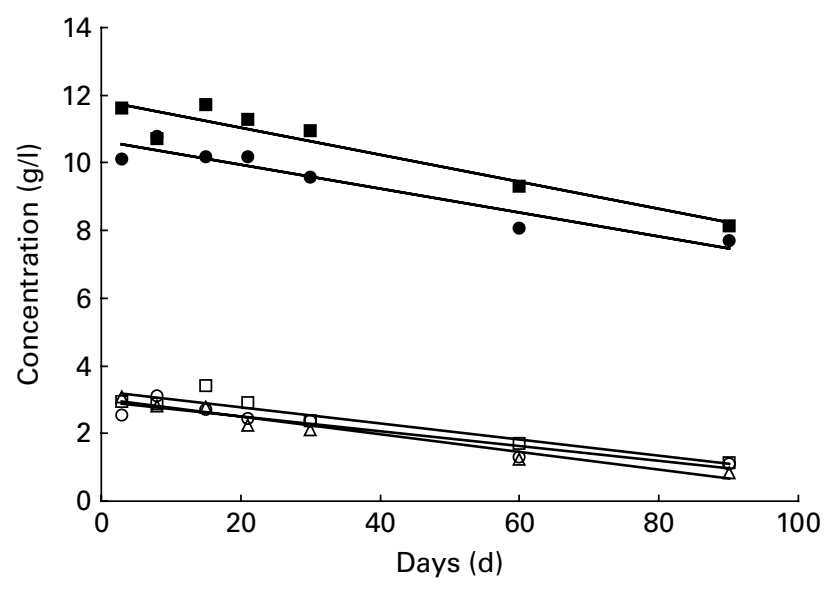

Fig. 2. Variation of neutral and acidic oligosaccharides. Neutral oligosaccharides in milk group $1(\bullet ; c=10.66-0.0355 d ; P<0.01)$ and milk group 3 $(\boldsymbol{\square} ; c=11.78-0.0391 d ; P<0.05)$, and acidic oligosaccharides in milk group $1(O ; c=2.95-0.0220 d ; P<0.01)$, milk group $2(\triangle ; c=3.05-0.0271 d$; $P<0.01)$ and milk group $3(\square ; c=3.26-0.0236 d ; P<0.01)$. All data symbols represent mean values of the corresponding oligosaccharide concentrations at seven points in time postpartum. However, statistical calculations are based on individual values. The trend line corresponding to the neutral oligosaccharide fraction of milk group 2 was not found to be significant $(P>0.05)$. 
Table 3. Structures of the acidic milk oligosaccharides determined in the present study

\begin{tabular}{|c|c|}
\hline $\begin{array}{l}\text { Name } \\
\text { (abbreviated) }\end{array}$ & Structure \\
\hline $3^{\prime}-S L$ & NeuAc $\alpha 2-3 G a l \beta 1-4 G l c$ \\
\hline $6^{\prime}-S L$ & NeuAc $\alpha 2-6 \mathrm{Gal} \beta 1-4 \mathrm{Glc}$ \\
\hline LSTa & NeuAc $\alpha 2-3 \mathrm{Gal} \beta 1-3 \mathrm{GlcNAc} \beta 1-3 \mathrm{Gal} \beta 1-4 \mathrm{Glc}$ \\
\hline LSTb & $\begin{array}{l}\text { Gal } \beta 1-3 \mathrm{GlcNAc} \beta 1-3 \mathrm{Gal} \beta 1-4 \mathrm{Glc} \\
\text { NeuAc } \alpha 2-6 /\end{array}$ \\
\hline LSTc & NeuAc $\alpha 2-6 \mathrm{Gal} \beta 1-4 \mathrm{GlcNAc} \beta 1-3 \mathrm{Gal} \beta 1-4 \mathrm{Glc}$ \\
\hline DSLNT & $\begin{array}{c}\text { NeuAc } \alpha 2-3 \mathrm{Gal} \beta 1-3 \mathrm{GlcNAc} \beta 1-3 \mathrm{Gal} \beta 1-4 \mathrm{Glc} \\
\text { NeuAc } \alpha 2-6 /\end{array}$ \\
\hline
\end{tabular}

$3^{\prime}$-SL, $3^{\prime}$-sialyl-lactose; $6^{\prime}$-SL, $6^{\prime}$-sialyl-lactose; LSTa-c, sialyl-lacto- $N$-tetraoses a-c; DSLNT, disialyl-lacto- $N$-tetraose.

group 1. Milk groups 2 and 3 revealed similar trends during the course of lactation. Due to low sample numbers, these changes were not always judged as significant (data not shown).

\section{Fucosylated neutral oligosaccharides}

Average concentrations of eleven fucosylated neutral oligosaccharides that were quantified in the present study are listed in Table 5. The major fucosylated carbohydrates in the samples of milk groups 1 and 3 were $2^{\prime}$-FL and LNFP I, as well as LNDFH I in the milk samples of group 1 . Non-secretors (milk group 2) predominantly biosynthesised 3-FL and LNFP II. These carbohydrates, as well as LNDFH II and $3^{\prime}$-F-LNH, were produced at a significantly higher level in non-secretor milks than in secretor milks. During the study period, concentrations of oligosaccharides typical for secretor milks, $2^{\prime}$-FL, LNFP I, $2^{\prime}$-F-LNH and $2^{\prime}, 3^{\prime}$ DFLNH, roughly decreased by half the amount, with the exception of LDFT, which did not alter significantly, and LNDFH I. 3-FL was the only oligosaccharide that steadily increased roughly twofold in all milk groups during the first 3 months of lactation. LNFP III also seemed to increase in secretor milks (groups 1 and 3), although this variation was not statistically significant. The concentrations of LNFP II, LNDFH I, LNDFH II and $3^{\prime}$-F-LNH in milk group 1 samples seemed to increase to maximum levels during the first month postpartum. After 3 months, mature milks contained lower amounts of these oligosaccharides as colostral milks.
In Table 6 and Fig. 3, the variation of fucosylated oligosaccharides during the course of lactation with regard to the three milk groups is summarised. Oligosaccharides were summed up on a molar basis according to four different linkage types: $\alpha 1,2$-fucose linked to terminal galactose (sum of $2^{\prime}$-FL, LDFT, LNFP I, LNDFH I, $2^{\prime}$-F-LNH and $2^{\prime}, 3^{\prime}$-DF$\mathrm{LNH}), \alpha 1,4$-fucose linked to subterminal $N$-acetylglucosamine (sum of LNFP II, LNDFH I and LNDFH II), $\alpha 1,3$-fucose linked to reducing glucose (sum of 3-FL, LDFT and LNDFH II) and $\alpha 1,3$-fucose linked to subterminal GlcNAc (sum of LNFP III, 3'-F-LNH and $2^{\prime}, 3^{\prime}$-DF-LNH.). These molar sum parameters reflect the complete biosynthetic capacity of various FucT during milk production. In addition, the different fucosyl linkage types can possibly be assigned to the action of specific glycosyltransferases. The former $\alpha 1,2-$ fucose moieties, typical for secretor milks, were expressed in significantly higher concentration in milk group 3 than in milk group 1. In both milk groups, these concentrations declined during the study period as indicated by significant straight lines of regression in Fig. 3. Fucose moieties with $\alpha 1,4$-bonds, products of the Lewis gene, were equally expressed in groups 1 and 2 (Table 6). At 2 and 3 weeks after birth, their concentrations seemed to reach maximum levels, with colostral concentrations resembling mature milk concentrations after 2 and 3 months postpartum. However, these trends were NS, and are therefore not shown in Fig. 3. Fucose moieties that are $\alpha 1,3$-linked to reducing glucose were detected in all three milk groups, especially in milk samples of group 2 representing the prevalent form of fucose. Increasing amounts of this fucose moiety were found during the study period, proving to be significant in the case of milk groups 1 and 2 (Fig. 3). Equally low levels of $\alpha 1$, 3-fucose residues linked to GlcNAc were detected in all milk groups, remaining relatively constant during the first $90 \mathrm{~d}$ of lactation.

\section{Acidic sialylated oligosaccharides}

Mean concentrations of the six acidic oligosaccharides determined in the present study are listed in Table 7. 6'-SL was quantitatively by far the most important acidic carbohydrate in all milks. Medium amounts of $3^{\prime}$-SL, LSTc and DSLNT were detected, whereas LSTa and LSTb did not occur at concentration levels above $0 \cdot 1 \mathrm{~g} / \mathrm{l}$. Average concentrations

Table 4. Concentrations $(\mathrm{mmol} / \mathrm{l})$ of core structures

\begin{tabular}{|c|c|c|c|c|c|c|c|c|c|c|}
\hline Group & Days & $n$ & Lac* $^{*}$ & Total core Lac* & LNT & Total core LNT & LNnT & Total core LNnT & LNH & Total core LNH \\
\hline 1 & 3 & 21 & $147 \cdot 0^{c}$ & $159 \cdot 5^{c}$ & $0.78^{b}$ & $4 \cdot 84^{\mathrm{b}, \mathrm{c}}$ & $0.49^{a}$ & $1 \cdot 37^{\mathrm{a}}$ & $0.06^{b}$ & $0.52^{b}$ \\
\hline 1 & 8 & 19 & $157 \cdot 8^{\mathrm{b}}$ & $169 \cdot 0^{\mathrm{b}}$ & $1.55^{\mathrm{a}}$ & $6 \cdot 37^{\mathrm{a}}$ & $0.48^{a}$ & $1.41^{\mathrm{a}}$ & $0 \cdot 17^{a}$ & $0.88^{a}$ \\
\hline 1 & 15 & 17 & $170 \cdot 9^{a}$ & $181 \cdot 4^{a}$ & $1.52^{\mathrm{a}}$ & $5.94^{a, b}$ & $0.28^{b}$ & $1.02^{b}$ & $0.14^{a}$ & $0.81^{a}$ \\
\hline 1 & 22 & 16 & $175 \cdot 3^{a}$ & $185 \cdot 7^{\mathrm{a}}$ & $1.59^{a}$ & $6 \cdot 09^{a, b}$ & $0.32^{b}$ & $1 \cdot 01^{b}$ & $0 \cdot 13^{a}$ & $0.76^{a}$ \\
\hline 1 & 30 & 14 & $167 \cdot 4^{a, b}$ & $176 \cdot 3^{a, b}$ & $1.41^{\mathrm{a}}$ & $5 \cdot 46^{a, b}$ & $0.23^{b}$ & $0.90^{b}$ & $0 \cdot 14^{a}$ & $0.79^{a}$ \\
\hline 1 & 60 & 12 & $175 \cdot 8^{a}$ & $184 \cdot 7^{\mathrm{a}}$ & $1.00^{b}$ & $3.94^{c}$ & $0.23^{b}$ & $0.81^{b}$ & $0.08^{b}$ & $0.46^{\mathrm{b}}$ \\
\hline 1 & 90 & 10 & $167 \cdot 9^{a, b}$ & $176 \cdot 3^{a, b}$ & $0.86^{b}$ & $3 \cdot 64^{c}$ & $0.20^{b}$ & $0 \cdot 81^{b}$ & $0.06^{b}$ & $0.34^{b}$ \\
\hline 1 & Average & 109 & $166 \cdot 0^{x}$ & $176 \cdot 3^{x}$ & $1 \cdot 24^{y}$ & $5 \cdot 18^{x}$ & $0.32^{x}$ & $1 \cdot 05^{x}$ & $0 \cdot 11^{x}$ & $0.65^{y}$ \\
\hline 2 & Average & 28 & $170 \cdot 1^{x}$ & $175 \cdot 9^{x}$ & $1 \cdot 68^{x}$ & $4 \cdot 07^{y}$ & $0 \cdot 11^{y}$ & $0.77^{y}$ & $0.08^{x}$ & $0.37^{z}$ \\
\hline 3 & Average & 17 & $161 \cdot 9^{x}$ & $174 \cdot 3^{x}$ & $1 \cdot 20^{y}$ & $5 \cdot 38^{x}$ & $0.32^{x}$ & $1 \cdot 00^{x, y}$ & $0.09^{x}$ & $0.84^{x}$ \\
\hline
\end{tabular}

Lac, lactose; LNT, lacto- $N$-tetraose; LNnT, lacto- $N$-neotetraose; $L N H$, lacto- $N$-hexaose.

a,b,c Mean values within a column with unlike superscript letters were significantly different $(P<0.05$; the Student-Newman-Keuls test for comparisons within group 1$)$.

$\mathrm{x}, \mathrm{y}, \mathrm{z}$ Least-squares means within a column with unlike superscript letters were significantly different $(P<0.05$; the Tukey-Kramer test for comparisons between groups).

* In some cases, the numbers of samples were slightly reduced. 
Table 5. Concentrations $(\mathrm{g} / \mathrm{l})$ of neutral fucosylated oligosaccharides

\begin{tabular}{|c|c|c|c|c|c|c|c|c|c|c|c|c|c|}
\hline Group & Days & $n$ & $2^{\prime}-\mathrm{FL}$ & 3-FL & LDFT & LNFP I & LNFP II & LNFP III & LNDFH I & LNDFH II & $2^{\prime}-\mathrm{F}-\mathrm{LNH}$ & $3^{\prime}-\mathrm{F}-\mathrm{LNH}$ & $2^{\prime}, 3^{\prime}$-DF-LNH \\
\hline 1 & 3 & 21 & $4 \cdot 13^{\mathrm{a}}$ & $0.24^{d}$ & $0.49^{\mathrm{a}}$ & $2 \cdot 00^{\mathrm{a}, \mathrm{b}}$ & $0.14^{\mathrm{a}}$ & $0.34^{\mathrm{a}}$ & $1 \cdot 12^{\mathrm{a}}$ & $0.10^{\mathrm{b}}$ & $0.21^{b}$ & $0.07^{c}$ & $0.35^{\star a, b}$ \\
\hline 1 & 8 & 19 & $3.37^{b}$ & $0.26^{d}$ & $0.33^{a}$ & $2 \cdot 25^{\mathrm{a}}$ & $0.23^{\mathrm{a}}$ & $0.34^{\mathrm{a}}$ & $1 \cdot 30^{\mathrm{a}}$ & $0 \cdot 17^{\mathrm{a}, \mathrm{b}}$ & $0.35^{a}$ & $0.18^{b}$ & $0.41^{\star a}$ \\
\hline 1 & 15 & 17 & $3.04^{b}$ & $0.38^{c, d}$ & $0.48^{\mathrm{a}}$ & $1.64^{\mathrm{a}, \mathrm{b}, \mathrm{c}}$ & $0.29^{a}$ & $0.37^{\mathrm{a}}$ & $1.46^{\mathrm{a}}$ & $0.23^{a}$ & $0.23^{a, b}$ & $0.22^{a, b}$ & $0.40^{\mathrm{a}}$ \\
\hline 1 & 22 & 16 & $3.02^{b}$ & $0.44^{\star b, c}$ & $0.36^{\mathrm{a}}$ & $1 \cdot 72^{\mathrm{a}, \mathrm{b}, \mathrm{c}}$ & $0.30^{a}$ & $0.37^{\mathrm{a}}$ & $1.55^{\star a}$ & $0.26^{\mathrm{a}}$ & $0.23^{a, b}$ & $0.24^{a}$ & $0.33^{\mathrm{a}, \mathrm{b}}$ \\
\hline 1 & 30 & 14 & $2 \cdot 96^{\mathrm{b}}$ & $0.42^{\mathrm{b}, \mathrm{c}}$ & $0.37^{\mathrm{a}}$ & $1.48^{b, c, d}$ & $0.24^{a}$ & $0.37^{\mathrm{a}}$ & $1 \cdot 36^{\mathrm{a}}$ & $0.24^{\mathrm{a}}$ & $0.24^{a, b}$ & $0 \cdot 20^{\mathrm{a}, \mathrm{b}}$ & $0.40^{\mathrm{a}}$ \\
\hline 1 & 60 & 12 & $2 \cdot 82^{b}$ & $0.56^{a, b}$ & $0.38^{a}$ & $1.06^{c, d}$ & $0.18^{a}$ & $0.40^{\mathrm{a}}$ & $1.02^{\mathrm{a}}$ & $0 \cdot 19^{a}$ & $0 \cdot 13^{\mathrm{b}}$ & $0.12^{\mathrm{c}}$ & $0.23^{b, c}$ \\
\hline 1 & 90 & 10 & $2 \cdot 59^{b}$ & $0.67^{\mathrm{a}}$ & $0.48^{\mathrm{a}}$ & $0.94^{d}$ & $0.17^{\mathrm{a}}$ & $0.44^{\mathrm{a}}$ & $1.05^{\mathrm{a}}$ & $0.17^{\mathrm{a}, \mathrm{b}}$ & $0.10^{\mathrm{b}}$ & $0.09^{C}$ & $0.18^{\mathrm{c}}$ \\
\hline 1 & Average & 109 & $3 \cdot 13^{y}$ & $0.42^{y}$ & $0.41^{x}$ & $1.58^{y}$ & $0.22^{y}$ & $0.38^{x}$ & 1.28 & $0.20^{y}$ & $0.21^{x}$ & $0 \cdot 16^{y}$ & $0.33^{y}$ \\
\hline 2 & Average & 28 & ND & $1.79^{x}$ & ND & ND & $1 \cdot 25^{x}$ & $0.38^{x}$ & ND & $0.45^{x}$ & ND & $0.35^{x}$ & ND \\
\hline 3 & Average & 17 & $4.57^{x}$ & $0 \cdot 15^{z}$ & $0.17^{y}$ & $3 \cdot 18^{x}$ & ND & $0.31^{x}$ & ND & ND & $0.26^{x}$ & $0 \cdot 13^{y}$ & $0.58^{x}$ \\
\hline
\end{tabular}

2'-FL, 2'-fucosyl-lactose; 3-FL, 3-fucosyl-lactose; LDFT, lactodifucotetraose; LNFP I-III, lacto- $N$-fucopentaoses I-III; LNDFH I-II, lacto-N-difucohexaoses I-II; 2'-F-LNH, $2^{\prime}$-fucosyl-lacto- $N$-hexaose; 3'-F-LNH, 3'-fucosyl-lacto- $N$-hexaose; $2^{\prime}, 3^{\prime}$-DF-LNH, 2', 3'-difucosyl-lacto- $N$-hexaose; ND, not detectable.

$\mathrm{a}, \mathrm{b}, \mathrm{c}, \mathrm{d}$ Mean values within a column with unlike superscript letters were significantly different $(P<0.05$; the Student-Newman-Keuls test for comparisons within group 1$)$.

${ }^{x, y, z}$ Least-squares means within a column with unlike superscript letters were significantly different $(P<0 \cdot 05$; the Tukey-Kramer test for comparisons between groups).

* The numbers of samples were slightly reduced.

of individual acidic oligosaccharides, though statistically different in some cases, did not vary to a great extent among the three milk groups, thus confirming the results of the whole carbohydrate fraction (Table 2).

Analogously, time effects, as listed in Table 7 with milk group 1, were similar to tendencies observed in the other milk groups (data not shown and Fig. 2). Concentrations of 6 -SL peaked in transitional milk at day 8 , but were reduced to at least one-third of the amount $90 \mathrm{~d}$ after birth. LSTc, also containing a Neu5Ac $\alpha 2-6 \mathrm{Gal}$ linkage, decreased in a similar manner (by a factor of 5 approximately) during the study period. $3^{\prime}$-SL was expressed in mature milk at a relatively constant level after a significant decrease in the first period of lactation. Concentrations of LSTa, a minor acidic sugar bearing a Neu5Ac 2 2-3Gal linkage, decreased after 1 week postpartum, so it could not be detected in several milk samples after 1 month. In contrast, concentrations of LSTb exhibiting a Neu5Ac $\alpha 2-6$ GlcNAc linkage increased during the first month and remained relatively constant thereafter. DSLNT, the only disialylated carbohydrate analysed and a kind of hybrid structure between LSTa and LSTb, exhibited a maximum time curve.

\section{Discussion}

Lac concentrations increased significantly in the case of milk group 1 (Table 4) and milk group 2 (data not shown) during the first 3 weeks of lactation. This result is in concurrence with previous reports ${ }^{(2,3)}$, although Lac concentrations seemed to be lower in the present study. Since the biosynthesis of nearly all milk oligosaccharides is based on the acceptor $\mathrm{Lac}^{(8,13,42)}$, the observed decrease of the oligosaccharide concentration during the course of lactation cannot be explained by a shortage of the acceptor molecule. Milk samples of groups 1 and 3 seemed to contain slightly lower Lac levels, although not judged as significant, compared with those of group 2 (Table 2). This possible effect could be counterbalanced by the much higher neutral oligosaccharide concentrations in the former milk groups.

Apart from Lac, six acidic sialylated oligosaccharides, three neutral core structures and eleven neutral fucosylated carbohydrates could be determined during the course of lactation by applying HPAEC. To date, only in the study done by Coppa et $a l^{(15)}$, an equally large number of individual carbohydrates were examined, whereas in other studies, approximately ten neutral oligosaccharides ${ }^{(25-28)}$ or to roughly ten acidic oligosaccharides $^{(29-31)}$ were examined. In the present study, we found differences in individual oligosaccharides in relation to lactation periods and, particularly, to the three main milk groups. To date, only few comparisons of several oligosaccharides among two milk groups have been drawn ${ }^{(24,25,28)}$.

\section{Fucosyloligosaccharides}

The predominant individual oligosaccharides in milk samples of secretor mothers (milk groups 1 and 3 ) were $2^{\prime}$-FL and LNFP I, consistent with qualitative and quantitative results of earlier reports ${ }^{(15,25,26)}$. The highest concentrations of $\alpha 1,2$-linked fucosyloligosaccharides, especially of $2^{\prime}$-FL, LNFP I and 2,3-DF-LNH (Table 5 and Fig. 3), were found

Table 6. Average concentrations (mmol/l) of fucose moieties

\begin{tabular}{lccccc}
\hline & & \multicolumn{4}{c}{ Linkage type } \\
\cline { 3 - 6 } Milk group & $n$ & Fuc $\alpha 1-2 G a l$ & Fuc $\alpha 1-4 G l c N A c$ & Fuc $\alpha 1-3 G l c$ & Fuc $\alpha 1-3 G l c N A c$ \\
\hline 1 & $104-108$ & $10.59^{\mathrm{b}}$ & $1.72^{\mathrm{a}}$ & $1.71^{\mathrm{b}}$ & $0.82^{\mathrm{a}}$ \\
2 & 28 & $\mathrm{ND}$ & $1.92^{\mathrm{a}}$ & $4.12^{\mathrm{a}}$ & $0.73^{\mathrm{a}}$ \\
3 & 17 & $13.99^{\mathrm{a}}$ & ND & $0.57^{\mathrm{c}}$ & $0.90^{\mathrm{a}}$ \\
\hline
\end{tabular}

Fuc $\alpha 1-2 \mathrm{Gal}, \quad \alpha 1,2$-fucose linked to terminal galactose; Fuc $\alpha 1-4 \mathrm{GlcNAc}, \alpha 1,4$-fucose linked to subterminal $\mathrm{N}$-acetylglucosamine; Fuc $\alpha 1$-3Glc, $\alpha 1,3$-fucose linked to reducing glucose; Fuc $\alpha 1-3 \mathrm{GlcNAc}, \alpha 1,3$-fucose linked to subterminal GIcNAc; ND, not detectable.

$\mathrm{a}, \mathrm{b}, \mathrm{c}$ Least-squares means (as a consequence of unbalanced data) within a column with unlike superscript letters were significantly different $(P<0.05$; the Tukey-Kramer test). 


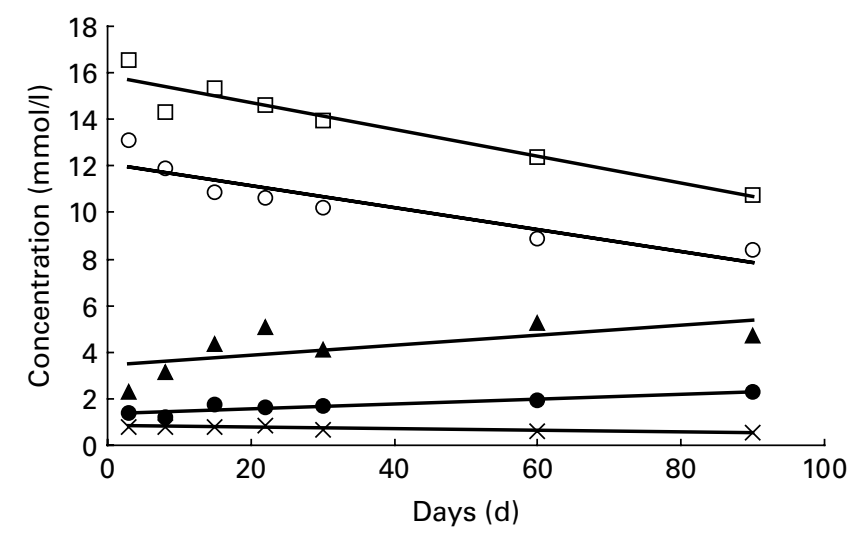

Fig. 3. Variation of $\alpha 1,2-, \quad \alpha 1,3-$ and $\alpha 1,4$-linked fucose moieties. Concentrations of $\alpha 1,2$-linked fucosyl moieties in milk group 1 $c=12.26-0.0512 d ; P<0.01)$ and milk group $3(\square ; c=15.89-0.0582 d$; $P<0.01$ ); $\alpha 1,3$-fucosyl moieties linked to reducing glucose in milk group 1 $(\bullet ; c=1.36+0.0106 d ; P<0.01)$ and milk group $2(\Delta ; c=3.29+0.0253 d$ $P<0.05) ; \alpha 1,3-$ fucosyl moieties linked to subterminal GlcNAc in milk group 2 ( $\times ; c=0.829-0.0031 d ; P<0.01$ ). All data symbols represent mean values of the corresponding oligosaccharide concentrations at seven points in time postpartum. However, statistical calculations are based on individual values. No significant trends $(P>0.05)$ were found with $\alpha 1$,4-linked fucosyl moieties and with $\alpha 1,3$-fucosyl moieties linked to reducing glucose in milk group 3 , nor with $\alpha 1,3$-fucosyl moieties linked to GlcNAc in milk groups 1 and 3 .

in the samples of milk group $3(\operatorname{Le}(a-b-))$, confirming the results reported by Newburg et al. ${ }^{(28)}$. It is generally acknowledged that these carbohydrates are synthesised by FucT II, which is encoded by the so-called secretor gene and preferentially accepts type 1 structures $^{(11,43)}$. LNT, a type 1 structure, represents the precursor of LNFP I. Similarly, Lac, which can be defined as the glucose analogue to type 2 chains $(\mathrm{Gal} \beta 1-4 \mathrm{GlcNAc})^{(28)}$, is the precursor of $2^{\prime}$-FL. Although molar concentrations of total core Lac exceeded those of the acceptor total core LNT by a factor of approximately 34 in milk group 1 (Table 4), the amount of $2^{\prime}$-FL and LDFT, the secretor enzyme products from Lac, surpassed by only $2 \cdot 3$ times the amount of LNFP I and LNDFH I, the corresponding products from LNT. Hence, at least a tenfold preference for type 1 chains can be deduced. In addition, we found that LNH was fucosylated to the same extent as LNT, which means that it was equally accepted by FucT II (data not shown). Ordinary type 2 chains obviously are not at all $\alpha 1,2$-fucosylated at the terminal galactose in milk oligosaccharides, because free carbohydrates containing $\mathrm{H}-2$ antigens, for example, $2^{\prime}$-fucosyl-lacto- $N$-neotetraose, had not been detected so $\operatorname{far}^{(8)}$. In agreement with previous reports $^{(15,25-27)}$, the concentration of the sum of $\alpha 1,2$-fucosyloligosaccharides decreased significantly within the first 3 months of lactation (Fig. 3). Therefore, one can conclude that the activity of the secretor enzyme (FucT II) is generally reduced during the course of lactation. However, since the acceptor core structures LNT and LNH with the exception of Lac declined in a similar manner during the study period (Table 4), it remains doubtful whether FucT II really became less active on type 1 structures.

The sum of $\alpha 1,4$-fucosyloligosaccharides detected (LNFP II, LNDFH I and LNDFH II) seemed to be slightly higher, although not significantly, in the samples of milk group 2 than in those of milk group 1 (Table 6). These carbohydrates are the main products of the Lewis enzyme (FucT III), which preferentially accepts type 1 chains, resulting in $\mathrm{Le}^{\mathrm{a}}$ or $\mathrm{Le}^{\mathrm{b}}$ antigens. We argue that non-secretor women (milk group 2) reveal a higher activity of the Lewis enzyme than the secretor women, because the precursor total core LNT is present in significantly lower amounts in the former (about $80 \%$, Table 4), whereas the Lewis products tended towards even higher concentrations. The Lewis enzyme was found to be about 100 times more efficient on H-type 1 substrates than on H-type 2 substrates ${ }^{(44)}$. Therefore, we concluded that $\mathrm{Le}^{\mathrm{x}}$ antigens, $\alpha 1,3$-fucose moieties linked to subterminal GlcNAc from type 2 chains, as found in LNFP III, $3^{\prime}-\mathrm{F}-\mathrm{LNH}$ and $2^{\prime}, 3^{\prime}-\mathrm{DF}-$ $\mathrm{LNH}$, are not or only to a minor extent products of the Lewis enzyme. The finding of similar concentrations of these $\alpha 1,3$-fucosyloligosaccharides in the samples of Le $(a-b-)$ women (milk group 3 in Table 6), which do not express FucT III, strongly supports this argument. It can be assumed that these oligosaccharides are biosynthesised by a third FucT, for example, the so-called plasma enzyme (FucT VI) that had been detected in human milk ${ }^{(45)}$. Even many other FucT could be involved, since human FucT IV, $\mathrm{V}$, VII, VIII and IX are also known to act as $\alpha 1,3-$ FucT $^{(11)}$.

3-FL, LDFT and LNDFH II, exhibiting fucose moieties $\alpha 1,3$-linked to reducing glucose, were found in the samples of milk group 1 in amounts that were approximately threefold

Table 7. Concentrations ( $\mathrm{g} / \mathrm{l})$ of acidic oligosaccharides

\begin{tabular}{|c|c|c|c|c|c|c|c|c|}
\hline Group & Days & $n$ & $3^{\prime}-S L$ & LSTa & DSLNT & LSTb & $6^{\prime}-S L$ & LSTC \\
\hline 1 & 3 & 21 & $0.35^{\mathrm{a}}$ & $0.06^{b}$ & $0.29^{b}$ & $0.05^{c}$ & $1 \cdot 31^{b}$ & $0.48^{a}$ \\
\hline 1 & 8 & 19 & $0.30^{a, b}$ & $0.09^{a}$ & $0.38^{a}$ & $0.06^{\mathrm{b}, \mathrm{c}}$ & $1 \cdot 77^{\mathrm{a}}$ & $0.53^{\mathrm{a}}$ \\
\hline 1 & 15 & 17 & $0 \cdot 27^{\mathrm{a}, \mathrm{b}}$ & $0.05^{\mathrm{c}, \mathrm{b}}$ & $0.44^{\mathrm{a}}$ & $0.07^{\mathrm{a}, \mathrm{b}, \mathrm{c}}$ & $1.57^{\mathrm{a}, \mathrm{b}}$ & $0.31^{b}$ \\
\hline 1 & 22 & 16 & $0 \cdot 26^{a, b}$ & $0.03^{c, d}$ & $0.41^{a}$ & $0.09^{a, b}$ & $1.42^{\mathrm{b}}$ & $0.25^{\mathrm{b}}$ \\
\hline 1 & 30 & 14 & $0.27^{\mathrm{a}, \mathrm{b}}$ & $0.03^{c, d}$ & $0.41^{\mathrm{a}}$ & $0.10^{\mathrm{a}}$ & $1.35^{\mathrm{b}}$ & $0.24^{b}$ \\
\hline 1 & 60 & 12 & $0.23^{b}$ & $0.01^{d}$ & $0.23^{b}$ & $0.08^{a, b, c}$ & $0.63^{\mathrm{c}}$ & $0.11^{\mathrm{c}}$ \\
\hline 1 & 90 & 10 & $0 \cdot 24^{\mathrm{b}}$ & $0.01^{d}$ & $0 \cdot 21^{\mathrm{b}}$ & $0.08^{a, b, c}$ & $0.49^{c}$ & $0.09^{c}$ \\
\hline 1 & Average & 109 & $0.27^{x, y}$ & $0.04^{x}$ & $0.34^{y}$ & $0.08^{y}$ & $1 \cdot 22^{x}$ & $0.29^{x}$ \\
\hline 2 & Average & 28 & $0 \cdot 24^{y}$ & $0.04^{x}$ & $0.42^{x}$ & $0.11^{x}$ & $1 \cdot 14^{x}$ & $0.21^{y}$ \\
\hline 3 & Average & 17 & $0.31^{x}$ & $0.06^{x}$ & $0.41^{x, y}$ & $0.08^{y}$ & $1 \cdot 31^{x}$ & $0.31^{x}$ \\
\hline
\end{tabular}

3'-SL, 3'-sialyl-lactose; LSTa-c, sialyl-lacto- $N$-tetraoses a-c; $6^{\prime}$-SL, $6^{\prime}$-sialyl-lactose; DSLNT, disialyl-lacto- $N$-tetraose. a,b,c,d Mean values within a column with unlike superscript letters were significantly different $(P<0.05 ;$ the Student-Newman-Keuls test for comparisons within group 1).

${ }^{x, y}$ Least-squares means within a column with unlike superscript letters were significantly different $(P<0.05$; the Tukey-Kramer test for comparisons between groups). 
higher than those found in the samples of milk group 3 (Tables 5 and 6). Obviously, women with no active Lewis enzyme produce only minor amounts of these carbohydrates. The Lewis enzyme isolated from human milk as well as a soluble form of the recombinant FucT III have been reported to link fucose also to the 3-O position of the reducing glucose of human milk oligosaccharides in reasonable amounts ${ }^{(46,47)}$. Therefore, we assumed that the major portions of these $\alpha 1,3$-fucosyloligosaccharides are also the products of the Lewis enzyme. A smaller portion should be due to many other FucT. The particularly high amounts of the Fuc $\alpha 1-$ 3 Glc motif in milk group 2, which are caused by high quantities of 3-FL and LNDFH II, can only be partially explained with an increased activity of the Lewis enzyme. Knowing that a common enzyme is involved in the biosynthesis of Fuc $\alpha 1-4$ GlcNAc- and Fuc $\alpha 1-3$ Glc motifs, similar variations during the course of lactation can be expected. However, $\alpha 1,4$-fucosyloligosaccharides seemed to exhibit maximal values during the first month after birth, whereas oligosaccharides containing the Fuc $\alpha 1-3$ Glc linkage significantly increased during the study period (Fig. 3).

\section{Sialyloligosaccharides}

In contrast to neutral carbohydrates, the six acidic oligosaccharides determined in the present study did not exhibit important differences among the three milk groups. This is not unexpected since these carbohydrates lacked fucose moieties. Several $\alpha 1,2-$ and $\alpha 1,4$-fucosylated acidic oligosaccharides that had been detected in human milk $^{(8,16)}$ should considerably vary among the various milk groups, but such components were not quantified in the present study. Concentrations of $6^{\prime}$-SL, the predominant acidic sugar in the present study, exceeded the amounts reported by other groups by at least twofold, whereas the concentrations of DSLNT were relatively low ${ }^{(15,29-31)}$. The amounts of $3^{\prime}-\mathrm{SL}, \mathrm{LSTa}$, LSTb and LSTc were in a range that was similar to that of the amounts detected by Asakuma et al. ${ }^{(30)}$, lower than the concentrations reported by Coppa et al. ${ }^{(15)}$ and higher than the values found by Bao et al. ${ }^{(31)}$. Although quantitative results obtained from different studies (including our report) revealed large differences, a significant decrease of the acidic sugar fraction as a whole and of most individual oligosaccharides was generally found during the first few months of lactation.

$6^{\prime}$-SL as well as LSTc declined in a similar manner, a fact that supports the hypothesis that a single sialyltransferase, possibly ST6GalI ${ }^{(48,49)}$, exclusively accepting type 2 structures, is involved in the biosynthesis of these carbohydrates. The more pronounced decrease of LSTc can be explained by a decrease of total core LNnT, the precursor of LSTc (Table 4), whereas the amounts of total core Lac, precursor of $6^{\prime}$-SL, remained constant after 2 weeks postpartum. $3^{\prime}$-SL decreased to a small extent during the study period, and could be synthesised by ST3Gal IV or also by ST3Gal VI, two $\alpha 2,3$-sialyltransferases preferentially accepting type 2 structures $^{(49)}$. Both we and Coppa et al. ${ }^{(15)}$ found that LSTa, a minor acidic sugar, declined very much and could not be or could only partially be detected after 2 and 3 months. We hypothesise that ST3Gal III, an $\alpha 2,3$-sialytransferase acting preferentially on type 1 structures $^{(49)}$, is involved in the biosynthesis of LSTa as well as of DSLNT. LSTb was the only acidic carbohydrate that increased within the first month postpartum, confirming previous results ${ }^{(15)}$. The so-called ST6GlcNAc could transfer sialic acid moieties to subterminal GlcNAc ${ }^{(49)}$ yielding LSTb as well as DSLNT, an oligosaccharide exhibiting both $\alpha 2,6$-linked and $\alpha 2,3$-linked Neu5Ac.

\section{Biological implications}

Human milk oligosaccharides resist digestion within the stomach and intestine ${ }^{(17,50,51)}$, and a significant proportion passes into the lower gastrointestinal tract. Here, the oligosaccharides, especially those compounds containing lacto- $N$-biose (type 1 structure) or GlcNAc, are thought to promote growth of a favourable gut flora in newborns ${ }^{(21-23,52)}$. The total core structures LNT and LNH, exhibiting lacto- $N$-biose units and representing the major GlcNAc-containing oligosaccharides in human milk, attain maximum levels after approximately 1 week postpartum but show an almost $50 \%$ decrease by 3 months postpartum. One could therefore conclude that newborns obtain the best protection from human milk oligosaccharides during the first few weeks of lactation, taking into account not only increasing milk volumes ${ }^{(53)}$ but also increasing baby weights during lactation. In addition, we found out that secretor women corresponding to milk groups 1 and 3 significantly produced higher amounts of these core structures than non-secretor women corresponding to milk group 2 . It remains to be investigated whether the gut flora of non-secretor mothers differs analogously with a lower occurrence of protective species, such as Bifidobacteria and Lactobacilli.

Several in vitro studies ${ }^{(19,54)}$, but also a clinical study ${ }^{(28)}$, have suggested the role of fucosyloligosaccharides, particularly $\alpha 1,2$-fucosyloligosaccharides, in reducing infectious diseases, including diarrhoea, which is carried out through inhibition of adherence of pathogens to epidermal surfaces by functioning as soluble competitive inhibitors of the host cell surface ligand and pathogen receptor interaction. Newburg et al. ${ }^{(28)}$ reported that babies fed with milk of Le $(\mathrm{a}-\mathrm{b}-$ ) mothers (milk group 3), exhibiting a high proportion of $\alpha 1,2$-fucosyloligosaccharides, were significantly less infected by stable toxin-Escherichia coli than babies fed with milk of Le $(a-b+)$ mothers (milk group 1). It can be hypothesised that newborns fed with milk of non-secretor mothers (group 2), lacking $\alpha$ 1,2-fucosylated oligosaccharides and $\mathrm{H}$-antigens, are even more susceptible to stable toxinE. coli. In this context, the relatively high frequencies of non-secretors (se/se) in Europe $(20 \%)$ compared with the low occurrence of non-secretors, for example, in the mestizo population of Mexico (1\%), have to be discussed ${ }^{(10,25,28,41)}$. The high incidence of secretors possibly evolved among the Mexican population also as a result of this pathogenic E. coli species. In other regions with a different evolutionary pressure of pathogens, non-secretors may be better apt to feed babies successfully, resulting in a higher incidence of this Lewis blood group. Apart from the above-mentioned $\mathrm{H}$-antigens, human milk oligosaccharides exhibit a variety of other antigenic determinants, such as $\mathrm{Le}^{\mathrm{a}}, \mathrm{Le}^{\mathrm{b}}$ and $\mathrm{Le}^{\mathrm{x}}$, depending upon the Lewis blood groups of the mothers as listed in Table 1. Interesting biological functions of these components are not unlikely ${ }^{(55,56)}$, and remain to be elucidated in more detail. 
Human milk oligosaccharides may also influence the infants on a systemic level. Obviously, they are partially absorbed in the intestine of babies, and can be detected in the urine of breast-fed infants ${ }^{(57)}$. Some evidence exists that milk oligosaccharides may function as anti-inflammatory factors, contributing to the lower incidence and severity of inflammatory diseases in breast-fed infants ${ }^{(17)}$. Particularly, sialic acid-containing oligosaccharides were found to inhibit the formation of platelet-neutrophil complexes and neutrophil activation $^{(58)}$. In addition, the acidic oligosaccharide fraction significantly inhibited leucocyte rolling and adhesion on epithelial cells ${ }^{(59)}$. In this context, the significant decrease of sialylated oligosaccharides during the course of lactation, as reported in the present study, could be biologically relevant.

\section{Acknowledgements}

The present research received no specific grant from any funding agency in the public, commercial or not-for-profit sectors. The authors declare no conflicts of interest. We are grateful to Manfred Fels, Danone Research, Friedrichsdorf, Germany, for data processing, and to Christina Hofmann, Fulda University of Applied Sciences, Germany, for performing Lac determinations. We thank Geraldine Groll, Petersberg, Germany, for the language revision. S. T. and J. H. designed the study, and J. H. supervised the clinical part of the study. B. S. supervised the analytical part of the study. B. M.-W. developed the chromatographic methods and analysed the milk samples. M. M. performed the data analyses. S. T. wrote the paper. B. S. and J. J. provided a lot of suggestions with regard to the content and concept of the manuscript. G. B. contributed to the discussion of the results and to the revision of the manuscript.

\section{References}

1. Montreuil J \& Mullet S (1960) Étude des variations des constituents glucidiques du lait de femme au cours de la lactation (Study of changes in carbohydrate constituents of human breast milk during lactation). Bull Soc Chim Biol 42, 365-377.

2. Viverge D, Grimmonprez L, Cassanas G, et al. (1985) Variations of lactose and oligosaccharides in milk from women of blood types secretor $\mathrm{A}$ or $\mathrm{H}$, secretor Lewis, and secretor $\mathrm{H} /$ nonsecretor Lewis during the course of lactation. Ann Nutr Metab 29, 1-11.

3. Coppa GV, Gabrielli O, Pierani P, et al. (1993) Changes in carbohydrate composition in human milk over 4 months of lactation. Pediatrics 91, 637-641.

4. Stahl B, Thurl S, Zeng J, et al. (1994) Oligosaccharides from human milk as revealed by matrix-assisted laser desorption/ ionization mass spectrometry. Anal Biochem 223, 218-226.

5. Kobata A, Yamashita K \& Tachibana Y (1978) Oligosaccharides from human milk. Methods Enzymol 50, 216-220.

6. Bruntz R, Dabrowski U, Dabrowski J, et al. (1988) Fucosecontaining oligosaccharides from human milk from a donor of blood group O Le(a) nonsecretor. Biol Chem Hoppe-Seyler 369, 257-273.

7. Haeuw-Fievre S, Wieruszeski JM, Plancke Y, et al. (1993) Primary structure of human milk octa-, dodeca- and tridecasaccharides determined by a combination of ${ }^{1} \mathrm{H}-\mathrm{NMR}$ spectroscopy and fast-atom bombardment mass spectrometry. Eur J Biochem 215, 361-371.
8. Boehm G \& Stahl B (2003) Oligosaccharides. In Functional Dairy Products, pp. 203-243 [T Mattila-Sandholm and M Scarela, editors]. Boca Raton: CRC Press.

9. Henry SM, Oriol R \& Samuelsson BE (1994) Detection and characterization of Lewis antigens in plasma of Lewis-negative individuals. Vox Sang 67, 387-396.

10. Oriol R, Le Pendu J \& Mollicone R (1986) Genetics of ABO, $\mathrm{H}$, Lewis, $\mathrm{X}$ and related antigens. Vox Sang 51, 161-171.

11. Ma B, Simala-Grant JL \& Taylor DE (2006) Review: fucosylation in prokaryotes and eukaryotes. Glycobiology 16, 158R-184R.

12. Watkins WM, Greenwell P, Yates AD, et al. (1988) Regulation of expression of carbohydrate blood group antigens. Biochimie 70, $1597-1611$.

13. Kobata A (1977) Milk glycoproteins and oligosaccharides. In The Glycoconjugates, vol. 1, pp. 423-440 [M Horowitz and W Pigman, editors]. New York: Academic Press.

14. Thurl S, Henker J, Siegel M, et al. (1997) Detection of four human milk groups with respect to Lewis blood group dependent oligosaccharides. Glycoconjugate J 14, 795-799.

15. Coppa GV, Pierani P, Zampini L, et al. (1999) Oligosaccharides in human milk during different phases of lactation. Acta Paediatr Suppl 430, 89-94.

16. Grönberg G, Lipniunas P, Lundgren T, et al. (1992) Structural analysis of five new monosialylated oligosaccharides from human milk. Arch Biochem Biophys 296, 597-610.

17. Donovan SM (2009) Invited Commentary: human milk oligosaccharides - the plot thickens. Br J Nutr 101, 1267-1269.

18. Bode L (2009) Human milk oligosaccharides: prebiotics and beyond. Nutr Rev 67, Suppl. 2, S183-S191.

19. Ruiz-Palacios MG, Cervantes LE, Ramos P, et al. (2003) Campylobacter jejuni binds intestinal $\mathrm{H}(\mathrm{O})$ antigen (Fuc $\alpha 1$, $2 \mathrm{Gal} \beta 1,4 \mathrm{GlcNAc})$, and fucosyloligosaccharides from human milk inhibit its binding and infection. J Biol Chem 278, $14112-14120$.

20. Kunz C, Rudloff S, Baier W, et al. (2000) Oligosaccarides in human milk: structural, functional and metabolic aspects. Aпnи Rev Nutr 20, 699-722.

21. György P, Norris RF \& Rose CS (1954) Bifidus factor. I. A variant of Lactobacillus bifidus requiring a special growth factor. Arch Biochem Biophys 48, 193-202.

22. Gauhe A, György P, Hoover JRE, et al. (1954) Bifidus factor. IV. Preparations obtained from human milk. Arch Biochem Biophys 48, 214-224.

23. Coppa GV, Zampini L, Galeazzi T, et al. (2006) Prebiotics in human milk: a review. Dig Liver Dis 38, Suppl. 2, S291-S294.

24. Viverge D, Grimmonprez L, Cassanas G, et al. (1990) Discriminant carbohydrate components of human milk according to donor secretor types. J Pediatr Gastroenterol Nutr 11, 365-370.

25. Erney RM, Malone WT, Skelding MB, et al. (2000) Variability of human milk neutral oligosaccharides in a diverse population. J Pediatr Gastroenterol Nutr 30, 181-192.

26. Chaturvedi P, Warren CD, Altaye M, et al. (2001) Fucosylated human milk oligosaccharides vary between individuals and over the course of lactation. Glycobiology 11, 365-372.

27. Sumiyoshi W, Urashima T, Nakamura T, et al. (2003) Determination of each neutral oligosaccharide in the milk of Japanese women during the course of lactation. Br J Nutr 89, 61-69.

28. Newburg DS, Ruiz-Palacios GM, Altaye M, et al. (2004) Innate protection conferred by fucosylated oligosaccharides of human milk against diarrhea in breastfed infants. Glycobiology 14, 253-263.

29. Martín-Sosa S, Martín MJ, García-Prado LA, et al. (2003) Sialyloligosaccharides in human and bovine milk and in infant formulas: variations with the progression of lactation. J Dairy Sci 86, 52-59. 
30. Asakuma S, Akahori M, Kimura K, et al. (2007) Sialyl oligosaccharides of human colostrum: changes in concentration during the first three days of lactation. Biosci Biotechnol Biochem 71, 1447-1451.

31. Bao Y, Zhu L \& Newburg DS (2007) Simultaneous quantification of sialyloligosaccharides from human milk by capillary electrophoresis. Anal Biochem 370, 206-214.

32. Thurl S, Müller-Werner B \& Sawatzki G (1996) Quantification of individual oligosaccharide compounds from human milk using high-pH anion-exchange chromatography. Anal Biochem 235, 202-206.

33. Thurl S, Henker J, Siegel M, et al. (1998) Lewis blood groups of breastfeeding women tested serologically and by chromatographic analysis of human milk oligosaccharides. Milchwissenschaft 53, 127-129.

34. Viverge D, Grimmonprez L, Cassanas G, et al. (1986) Diurnal variations and within the feed in lactose and oligosaccharides of human milk. Ann Nutr Metab 30, 196-209.

35. Neville MC, Keller RP, Casey CE, et al. (1984) Studies on human lactation. I. Within-feed and between-breast variation in selected components of human milk. Am J Clin Nutr 40, 635-646.

36. Thurl S, Henker J, Taut H, et al. (1993) Variations of neutral oligosaccharides and lactose in human milk during the feeding. Z Ernährungswiss 32, 262-269.

37. Wiederschain GY \& Newburg DS (2001) Glycoconjugate stability in human milk: glycosidase activities and sugar release. J Nutr Biochem 12, 559-564.

38. Bertino E, Coppa GV, Giuliani F, et al. (2008) Effects of Holder pasteurization on human milk oligosaccharides. Int $J$ Immunopathol Pharmacol 21, 381-385.

39. Beutler HO (1984) Lactose and D-galactose. In Methods in Enzymatic Analysis, vol. 6, pp. 104-112 [HU Bergmeyer, editor]. Weinheim, Deerfield Beach, Basel: Verlag Chemie.

40. SAS Institute Inc (2002-2003) SAS/STAT. Release 9.1. Cary, NC: SAS Institute, Inc.

41. Musumeci M, Simpore J, D'Agata A, et al. (2006) Oligosaccharides in colostrum of Italian and Burkinabe women. J Pediatr Gastroenterol Nutr 43, 372-378.

42. Kobata A (2004) Minireview: the third chains of living organisms - a trail of glycobiology that started from the third floor of building 4 in NIH. Arch Biochem Biophys 426, 107-121.

43. Kumazaki $\mathrm{T}$ \& Yoshida A (1984) Biochemical evidence that secretor gene, $\mathrm{Se}$, is a structural gene encoding a specific fucosyltransferase. Proc Natl Acad Sci U S A 81, 4193-4197.

44. Costache M, Apoil PA, Cailleau A, et al. (1997) Evolution of fucosyltransferase genes in vertebrates. J Biol Chem 272, 29721-29728.

45. Mollicone R, Gibaud A, Francois A, et al. (1990) Acceptor specificity and tissue distribution of three human $\alpha$-3-fucosyltransferases. Eur J Biochem 191, 169-176.
46. Johnson PH, Donald ASR, Feeney J, et al. (1992) Reassessment of the acceptor specificity and general properties of the Lewis blood-group gene associated $\alpha$-3/4-fucosyltransferases purified from human milk. Glycoconjugate J 9, 251-264.

47. Costa J, Grabenhorst E, Nimtz M, et al. (1997) Stable expression of the golgi form and secretory variants of human fucosyltransferase III from BHK-21 cells. $J$ Biol Chem 272, $11613-11621$

48. Legaigneur P, Breton C, Battari AE, et al. (2001) Exploring the acceptor substrate recognition of the human B-galactoside a2,6-sialyltransferase. J Biol Chem 276, 21608-21617.

49. Harduin-Lepers A, Vallejo-Ruiz V, Krzewinski-Recchi MA, et al. (2001) The human sialyltransferase family. Biochimie 83, 727-737.

50. Engfer MB, Stahl B, Finke B, et al. (2000) Human milk oligosaccharides are resistant to enzymatic hydrolysis in the upper gastrointestinal tract. Am J Clin Nutr 71, 1589-1596.

51. Gnoth MJ, Kuntz C, Kinne-Saffran E, et al. (2000) Human milk oligosaccharides are minimally ingested in vitro. J Nutr 130, 3014-3020.

52. Wada J, Ando T, Kiyohara M, et al. (2008) Bifidobacterium bifidum lacto- $N$-biosidase, a critical enzyme for the degradation of human milk oligosaccharides with a type 1 structure. Appl Environ Microbiol 74, 3996-4004.

53. Neville MC, Keller R, Seacat J, et al. (1988) Studies in human lactation: milk volumes in lactating women during the onset of lactation and full lactation. Am J Clin Nutr $\mathbf{4 8}$, 1375-1386.

54. Cravioto A, Tello A, Villafán $\mathrm{H}$, et al. (1991) Inhibition of localized adhesion of enteropathogenic Escherichia coli to Hep-2 cells by immunoglobulin and oligosaccharide fractions of human colostrum and breast milk. J Infect Dis 163, $1247-1255$.

55. Jiang X, Huang P, Zhong W, et al. (2004) Human milk contains elements that block binding of noroviruses to human histo-blood group antigens in saliva. J Infect Dis 190, 1850-1859.

56. Sinclair HR, Smejkal CW, Glister C, et al. (2008) Sialyloligosaccharides inhibit cholera toxin binding to the GM1 receptor. Carbohydrate Res 343, 2589-2594.

57. Obermeier S, Rudloff S, Pohlentz G, et al. (1999) Secretion of ${ }^{13} \mathrm{C}$-labelled oligosaccharides into human milk and infant's urine after oral [13]galactose load. Isotopes Environ Health Stud 35, 119-125.

58. Bode L, Rudloff S, Kunz C, et al. (2004) Human milk oligosaccharides reduce platelet-neutrophil complex formation leading to a decrease in neutrophil $\beta 2$ integrin expression. $J$ Leukoc Biol 76, 820-826.

59. Bode L, Kunz C, Muhly-Reinholz M, et al. (2004) Inhibition of monocyte, lymphocyte, and neutrophil adhesion to endothelial cells by human milk oligosaccharides. Thromb Haemost 92, $1402-1410$. 